\title{
Caracterización y Evaluación de Tobas Puzolánicas en el Sur del Ecuador, Caso de Estudio "Yamana" Cantón Paltas, Provincia de Loja
}

\author{
Guamán, Galo $^{\text {1, * iD ; Ubidia, Carlos }}{ }^{1}$ iD; Gualpa, Wilman ${ }^{1}$ id \\ ${ }^{1}$ Universidad Técnica Particular de Loja, Departamento de Geología y Minas e Ingeniería Civil, Loja, Ecuador
}

\begin{abstract}
Resumen: En el presente artículo se presentan los resultados de la evaluación de la actividad puzolánica de tobas ubicadas en Barrial Blanco al sur del Ecuador. La metodología incluye ensayos físicos (módulo de finura, índice de puzolanidad, densidad de roca), químicos (pérdida por ignición, fluorescencia de rayos x y difracción de rayos x) y geofísicos (tomografía eléctrica vertical), La actividad puzolánica se determinó a partir de la resistencia a la compresión, según la norma ASTM C311 y C618. Dicho depósito tiene como recurso un total de 323680030 Tm de material aglomerante con un índice de puzolanidad promedio de $83,91 \%$, determinado a partir de una resistencia media de 11,74 MPa de resistencia al corte tomando en cuenta la dosificación especificada para el desarrollo del ensayo. A su vez cuenta con una gran ventaja al poseer un $0,00109 \mathrm{~m} 3 /$ Ton de coeficiente de destape, ya que las rocas afloran en superficie. Finalmente, se categoriza el depósito a nivel de recurso indicado dentro de los márgenes de la clasificación JORC (1999) de recursos y reservas, ya que cuenta con un nivel de confianza razonable, pero no con un alto grado de certidumbre.
\end{abstract}

Palabras clave: puzolana, tobas puzolánicas, recursos, Yamana, Barrial Blanco.

\section{Characterization and Evaluation of Pozzolanic Tuffs in Southern Ecuador, Case Study "Yamana" Paltas Canton, Province of Loja}

\begin{abstract}
This article presents the results of the evaluation of the pozzolanic activity of tuffs in Barrial Blanco of South Ecuador. The methodology includes physical (fineness modulus, pozzolanity index, rock density), chemical (loss on ignition, x-ray fluorescence and x-ray diffraction) and geophysical tests (vertical electrical tomography), pozzolanic activity was determined from compressive strength, according to ASTM C311 and C618. Said deposit has as a resource a total of $323680030 \mathrm{Tm}$ of binder material with an average pozzolanity index of $83.91 \%$, determined from an average resistance of $11.74 \mathrm{MPa}$ of shear resistance considering the dosage specified for the development of the trial. At the same time, it has a great advantage as it has a $0.00109 \mathrm{~m} 3$ / Ton of uncovering coefficient, since the rocks emerge on the surface. Finally, the deposit is categorized at the indicated resource level within the margins of the JORC (1999) classification of resources and reserves, since it has a reasonable level of confidence, but not a high degree of certainty.
\end{abstract}

Keywords: pozzolana, pozzolanic tuffs, resources, Yamana, Barrial Blanco.

\section{INTRODUCCIÓN}

Las rocas y minerales industriales son el sector minero menos conocido de la economía nacional. Paladines (2010) indica que, según datos del Banco Central del Ecuador de los 32 sectores de la economía nacional, solo uno no precisa de insumos mineros (alquiler de vivienda), mientras que los 31 restantes los requieren, ya sea en forma de materia prima o como productos semielaborados y elaborados.
La industria minera no metálica al sur del Ecuador no está bien explorada, sin embargo, tiene mucho potencial. Actualmente las concesiones adjudicadas en esta región se limitan a arcillas, materiales pétreos como gravas, arena y a la explotación de oro en aluviales. Investigaciones realizadas por Malla (2016) en el cantón Saraguro logró determinar en diferentes sectores tobas con actividad Puzolánica con enorme potencial para la industria de la construcción, Cañicapa y Zunin son los centros que abastecen de material para la construcción en la zona. Más tarde Campoverde y Narváez (2017), lograron descubrir materiales tobáceos con actividad Puzolánica en los cantones de Gonzanamá y Paltas, con sitios potenciales en Purunuma y Barrial Blanco. 
En esta investigación los autores se centraron en la exploración y cuantificación del material puzolánico del sector conocido como Barrial Blanco ubicado en la parroquia Yamana, cantón Paltas de la provincia de Loja a través de la caracterización por medio de ensayos de laboratorio, evaluación de la potencia del depósito con la ayuda de tomografía de resistividad eléctrica (TRE) y mediante el método de los perfiles para cuantificar y categorizar el material en términos de recursos indicados.

Teniendo en cuenta el proceso de producción del cemento portland y los costos que implica, considerar el uso de puzolanas como insumo puede evidentemente reducir costos para la construcción en todo el alcance que el término abarca, especialmente para el sector inmobiliario si tomamos en cuenta el nivel de pobreza de las zonas rurales del sur del país.

\subsection{Geomorfología del Área de Estudio}

La parroquia Yamana, perteneciente al cantón Paltas, provincia de Loja, se ubica en la parte centro del cantón (Fig. 1), entre las parroquias Cangonamá al norte, Catacocha al sur, San Antonio al este y Casanga al oeste. El material aglomerante se ubica al sur del sector Barrial Blanco. Geormorfológicamente la zona de estudio se ubica en la cuenca Alamor-Lancones y forma un valle alargado de orientación NE-SW denominado "Valle de Casanga" esta depresión se encuentra formada por una serie de relieves colinados mayormente disectados y conformados por areniscas y conglomerados, grandes coluviales forman rellanos con superficies suaves además de relieves estructurales limitados por fallas regionales de dirección preferente SW-NE. Formando dos estructuras prominentes, al este del valle se aprecian dos superficies de cuestas moderadamente disectadas con buzamientos suaves hacia el noreste y limitadas en su flanco oeste por escarpes subverticales. Las cuestas han sido definidas en campo como cuesta norte y cuesta sur, siendo la primera con mayor potencial puzolánico y de mayor facilidad de acceso, la cuesta sur está cubierta por una densa vegetación de régimen seco y es de difícil acceso. Estas geoformas tienen cotas que oscilan entre los 1240 a 980 m.s.n.m.

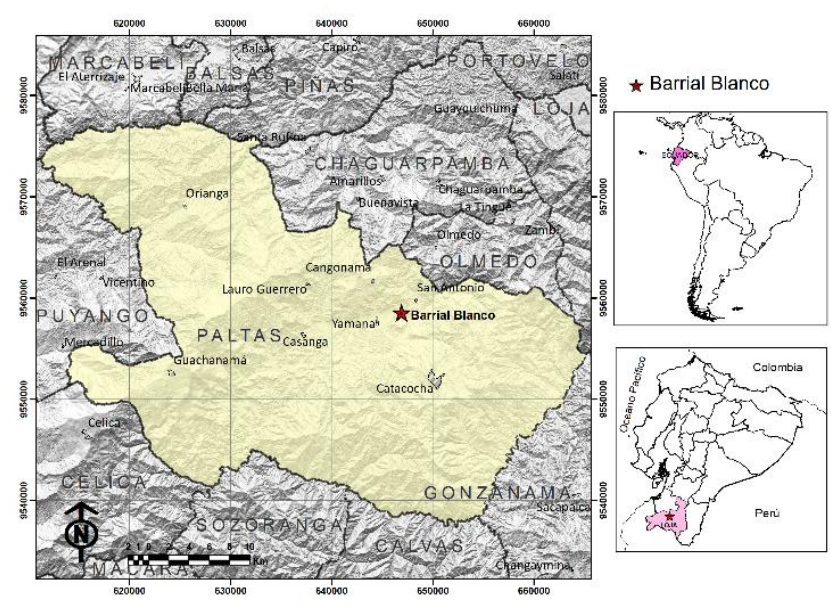

Figura 1. Mapa de ubicación del sitio Barrial Blanco en el cantón Paltas, parroquia Yamana al sur del Ecuador

\section{CONTEXTO GEOLÓGICO REGIONAL}

Autores como Jaillard et al, (1999), Kenerly (1973) o Hungerbühler (2002) coinciden en que el valle de Casanga se encuentra perteneciendo a la Cuenca Sedimentaria Río Playas, la misma que a su vez corresponde a la parte noreste de la Cuenca Alamor-Lancones donde afloran rocas sedimentarias de edades Cretácico Tardío y Paleógenas (Jaillard, et al., 1999). La estratigrafía de la zona ha sido poco estudiada y aunque INIGEM (2017) formuló nuevas unidades en la cuenca existen algunas secuencias que estratigráficamente podrían no corresponder. A continuación, se describe estas secuencias, tomando información de INIGEMM (2017) y otros autores (Fig. 2).

El basamento de la cuenca corresponde a lavas basálticas y gabros de la Formación Punta de Piedra de edad Cretácico Temprano (Egüez y Poma, 2001), sobreyacida transicionalmente por la Unidad Celica compuesta por brechas, lavas basalto - andesíticas, hialoclastitas e intruída por el Batolito de Tangula. La Unidad Bramaderos de edad Albiense-Cenomaniense (Jaillard et al, 1999) sobreyace en contacto transicional a la Unidad Celica y consta de aglomerados, tobas, grauvacas y esporádicamente lavas basáltico-andesíticas y constituye la base de las unidades sedimentarias Naranjo y Casanga, las mismas que se encuentran sobreyaciéndola discordantemente. La Unidad La Ramada constituye una secuencia de tobas aglomeráticas grises, se encuentran sobreyaciendo en concordancia a la secuencia volcanoclástica de la Unidad Bramaderos y subyaciendo en discordancia a la Unidad Naranjo. Debido a su posición estratigráfica se le asigna una edad TuronienseConiaciense. La Unidad Naranjo y Unidad Casanga están formadas por sedimentos depositados en ambientes de abanicos submarinos (Vallejo, 2017). Jaillard et al. (1996) estima el espesor de la Unidad Casanga entre 200 y $400 \mathrm{~m}$, Hungerbuhler (2002) la ubica entre el Campaniense Tardío y Maastrichtiense Temprano, mientras que Vallejo (2017) la ubica entre el Albiano a Santoniano. La Formación Rio Playas, compuesta de conglomerados y areniscas cubren la Unidad Casanga y se la considera de edad Paleoceno-Eoceno (Vallejo, 2017). Sobreyaciendo a esta Unidad en el sector de Cerro Pueña y parte alta de La Merced afloran tobas riolíticas y lavas que fue fechada por Hungerbuhler (2002) con una edad Oligoceno cerca del sitio Barrial Blanco (Fig. 1 y 2) y que corresponderían a la Unidad Loma Blanca sin embargo bajo estas secuencias afloran tobas dacíticas-riolíticas que quizás no fueron datadas y que corresponderían a rocas del Paleoceno de la Formación Sacapalca.

Las rocas con actividad puzolánica, correspondería a rocas de la Unidad Loma Blanca, que generalmente se encuentran meteorizadas y le dan un aspecto blanquecino a toda la zona (Fig. 10) claramente visible a través de fotografías aéreas y Google Earth. Geomorfológicamente las tobas se encuentran sobre dos superficies de cuestas estructurales denominadas en este estudio como cuesta norte y sur, precisamente el estudio se centra en la cuesta norte por su fácil accesibilidad y poca cobertura boscosa, aunque algunos puntos también se tomaron en la cuesta sur. 

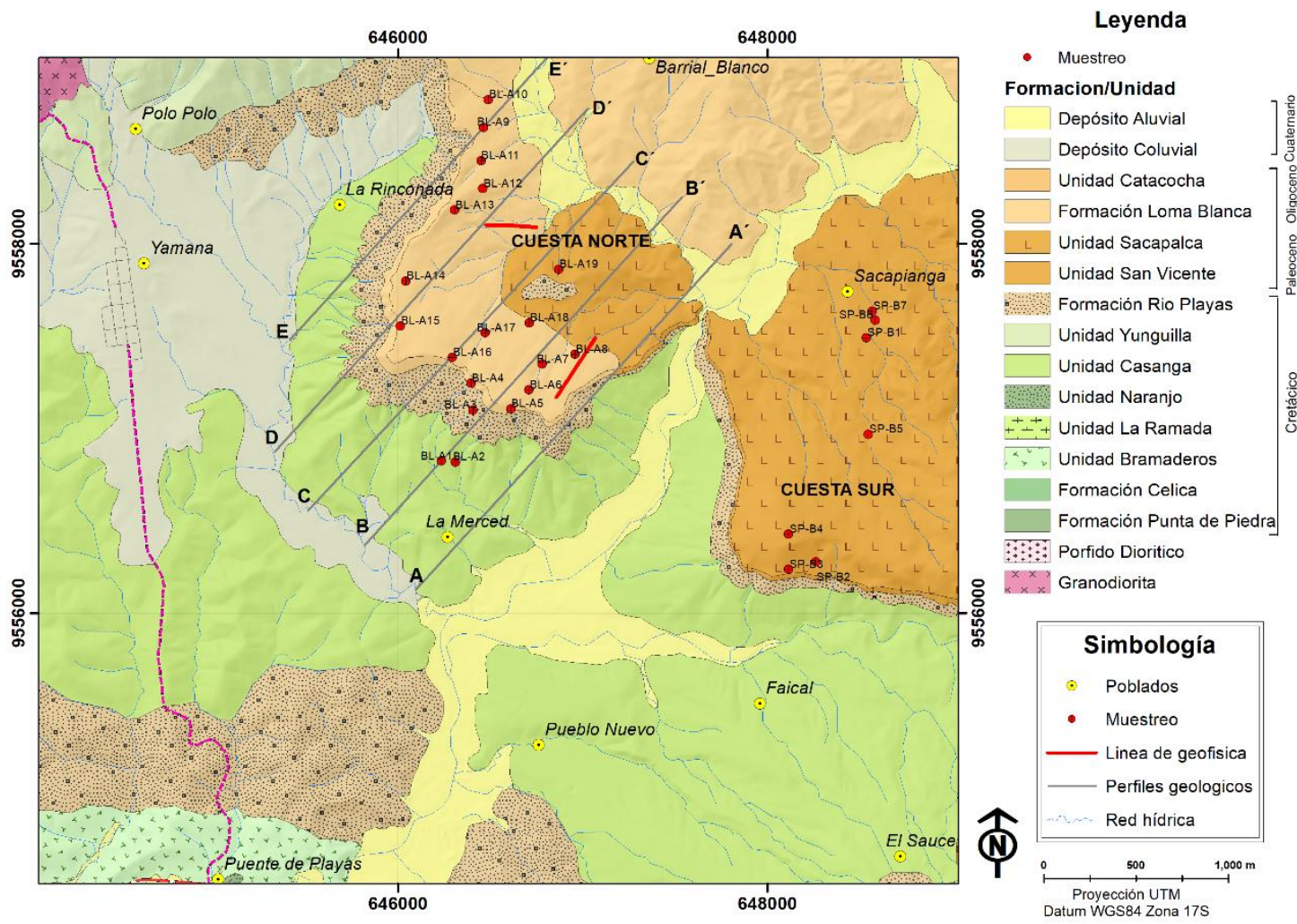

Figura 2. Mapa Geológico elaborado por los autores tomando como referencia la Hoja 39 edición 3, 2017 del INIGEMM

\section{METODOLOGÍA}

La metodología consistió en 4 etapas bien definidas (Fig. 3). La etapa uno inicia con la recopilación de información con el fin de tener una línea base de información geológica y las normas vigentes para el análisis de este recurso. Luego la etapa dos de campo donde se realiza el levantamiento geológico con la documentación de afloramientos y la recolección de muestras, así como los ensayos de exploración a través de tomografía eléctrica bajo la configuración de los electrodos Wenner-Schlumberguer debido a su facilidad para mover los electrodos usando para las lecturas y mediciones el Terrámetro SAS 4000 en dos líneas, una de 400 metros con 81 electrodos distribuido cada 5 metros y otra de 300 metros con 61 electrodos cada 5 metros, esto permitió definir en profundidad la potencia del material tobáceo. La etapa tres se realiza en laboratorio donde las muestras son procesadas y sometidas a análisis químico como pérdida por ignición (norma ASTM C114 - 04) donde se determina el contenido de agua, carbonatos que se descomponen liberando $\mathrm{CO} 2$, sulfatos y sulfuros que liberan $\mathrm{SO}$ 2, tomando como referencia la pérdida de masa que sufre la muestra al ser expuesta a un incremento de temperatura con relación al peso inicial que posee antes de aplicarse el ensayo, según la norma este valor no debe superar el $10 \%$, fluorescencia de rayos $\mathrm{x}$ con el equipo de espectrometría Brucker S-1 Turbo bajo la modalidad de Minning Light Elements, análisis físicos como módulo de finura bajo la norma ASTM C184-94, índice de puzolanidad bajo la norma ASTM C 311-02, peso específico de roca bajo la norma ASTM C 188-17, realizado mediante el uso del picnómetro en el cual se tomó en cuenta 4 medidas que son las siguientes:
Peso del picnómetro vacío (P1)

Peso del picnómetro + muestra $(\mathrm{P} 2)$

Peso picnómetro + agua (P3)

Peso picnómetro + agua + muestra $(\mathrm{P} 4)$

$$
\mathrm{PE}=\frac{\mathrm{P} 2-\mathrm{P} 1}{(\mathrm{P} 3-\mathrm{P} 1)-(\mathrm{P} 4-\mathrm{P} 2)}
$$

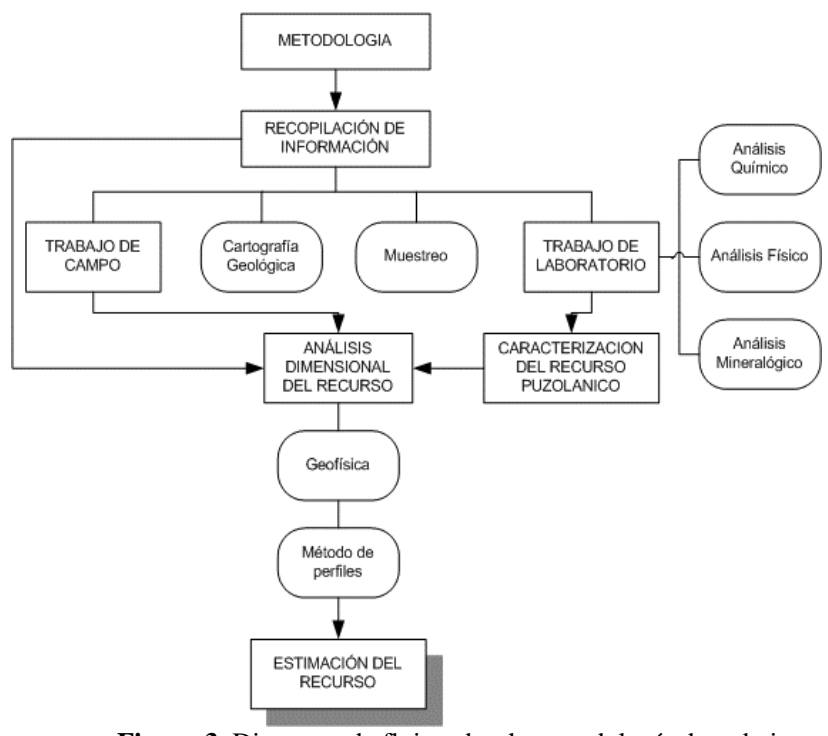

Figura 3. Diagrama de flujo sobre la metodología de trabajo

Se realizaron análisis mineralógicos mediante difracción de rayos $\mathrm{x}$ con el equipo Bruker D8 Advanced y análisis al microscopio de láminas delgadas y muestras de mano de roca. 
Para el presente caso de estudio se consideró oportuno basarse principalmente en tres especificaciones para catalogar el material como puzolanas naturales:

- La suma total de la composición química del material entre la cantidad de sílice, aluminosilicatos y óxidos de hierro no debe ser menor al $70 \%$.

- La cantidad total de materia orgánica, carbonatos, sulfatos y sulfuros presentes no deben ser mayores al $10 \%$ del total en peso.

- El índice de actividad puzolánico no debe ser menor al $75 \%$.

La normativa sugiere una dosificación establecida en donde se utilizan $500 \mathrm{~g}$ de cemento portland, $1375 \mathrm{~g}$ de arena fina gradada y $242 \mathrm{ml}$ de agua para la mezcla de control (Fig. 4a y b). Esta cantidad está fijada para 6 morteros de forma cúbica encofrados en moldes estándar de 5 x 5 x $5 \mathrm{~cm}$ (Fig. 4c). Sin embargo, la dosificación puede variar según la resistencia que se pretenda alcanzar y la fluidez de la mezcla que permiten una mejor trabajabilidad de los morteros. Una vez definida la mezcla estándar, el procedimiento indica proceder con la sustitución al $20 \%$ de puzolanas por el cemento portland. Finalmente, al término de 7 días de curado en agua se realiza la rotura sometiendo los morteros a esfuerzo y se determina la resistencia en base al área de contacto entre la superficie del mortero y la prensa (Fig. 4d). Según la norma ASTM 618 "Standard Specification for Coal Fly Ash and Raw or Calcined Natural Pozzolan for Use in Concrete" el índice de actividad puzolánica que se realiza según la norma ASTM C 311-02 para puzolanas de tipo "N" al cabo de 7 días debe encontrarse por encima del $75 \%$.

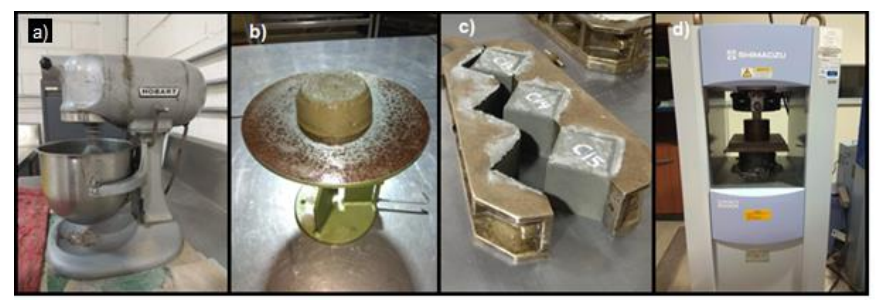

Figura 4. a) Preparación de la mezcla para morteros. b) Ensayo de fluidez. c) Desencofrado de morteros. d) Resistencia a la compresión simple de morteros

En la etapa final se realiza la compilación, edición, y cálculos correspondientes, con la información obtenida y generada además se evalúa el recurso puzolánico, en cuanto a si el material cumple las normas establecidas para su denominación puzolánica sobre los parámetros descritos en la norma ASTM C 618 "Standard Specification for Coal Fly Ash and Raw or Calciner Natural Pozzolan For Use in Concrete". Y se realiza el cálculo del tonelaje de las tobas puzolánicas, categorizándolas bajo el código JORC (1999) que, según Stephenson P, R (2001) es una estimación del tonelaje (o volumen) y ley (o calidad) como recurso mineral o reserva de mineral y para la subdivisión de cada uno en categorías. Estos recursos minerales se subdividen, en orden ascendente de la confianza geológica, en categorías de Inferidos, Indicados y Medidos.

Para la evaluación del tonelaje se empleará el método de los perfiles geológicos que se basa en las siguientes ecuaciones presentadas por Bustillo Revuelta \& López Jimeno (1997):

$$
\mathrm{V}=\frac{\mathrm{A}_{1}+\mathrm{A}_{2}}{2} \times \mathrm{D}_{1-2}
$$

Dónde:

$\mathrm{V}=$ volumen del yacimiento $(\mathrm{m} 3)$

$\mathrm{A} 1=$ área del perfil número uno $(\mathrm{m} 2)$

$\mathrm{A} 2=$ área del perfil número dos $(\mathrm{m} 2)$

D1-2= Distancia comprendida entre el perfil uno y perfil dos (m)

El proceso se realiza una vez determinados los contactos geológicos, los perfiles geofísicos (Fig. 8) y geológicos (Fig. 9), además de columnas estratigráficas. Para ello se realiza 5 perfiles en dirección suroeste - noreste (Fig. 2) a través de la cuesta principal con una distancia de separación de 400 metros entre cada uno, el área de las secciones se construye y calcula en GIS (Fig. 8).

Para el cálculo de los extremos, se debe usar el área próxima al cierre por la distancia del perfil más próximo al límite de dicho cierre.

$$
\mathrm{V}=\frac{\mathrm{S} * \mathrm{D}}{2}
$$

Dónde:

$\mathrm{V}=$ volumen sección $(\mathrm{m} 3)$

$\mathrm{S}=$ área próxima al cierre $(\mathrm{m} 2)$

$\mathrm{D}=$ distancia del perfil más próximo al límite $(\mathrm{m})$

Finalmente, el cálculo del tonelaje de material es necesario la sumatoria de volúmenes de acuerdo con el número de perfiles planteados, multiplicado por la densidad del material estudiado.

$$
\text { Ton }=\mathrm{V} \times \rho
$$

Dónde:

Ton= tonelaje del yacimiento $(\mathrm{tn})$

$\mathrm{V}=$ volumen del yacimiento $(\mathrm{m} 3)$

$\rho=$ densidad del material $(\mathrm{tn} / \mathrm{m} 3)$

Finalmente una vez concluido el análisis dimensional del depósito, se procede a calcular su coeficiente de destape, el mismo que es el cociente entre la cantidad de material estéril y el de material útil del yacimiento o depósito, aplicando la siguiente fórmula según Bustillo Revuelta \& López Jimeno (1997).

$$
\mathrm{K}_{\mathrm{m}}=\frac{\mathrm{V}_{\mathrm{e}}}{\mathrm{R}_{\mathrm{m}}}
$$

Dónde:

$\mathrm{Km}=$ Coeficiente medio de destape

$\mathrm{Ve}=$ Volumen total de estéril a destapar

$\mathrm{Rm}=$ Tonelaje de reservas de material a extraer

\section{RESULTADOS}

La campaña de muestreo se desarrolló mayormente en la cuesta estructural norte por su mayor accesibilidad y material aflorante meteorizado. Se recolectaron muestras de aproximadamente $25 \mathrm{Kg}$ cada $300 \mathrm{~m}$ a priori (Fig. 2) con el fin de evaluar los materiales e interpretar la naturaleza y 
características del depósito puzolánico para finalmente categorizar y cuantificar el recurso. Las rocas aflorantes están compuestas de tobas de cristales de composición riolítica indicado por INIGEMM (2017) en la carta de Cariamanga. Estas rocas forman superficies blanquecinas en casi toda el área de la cuesta norte (Fig 10 A) denominado como Barrial Blanco por su cercanía a este poblado (Fig. $10 \mathrm{C}$ y D). En la cuesta sur denominada Sacapianga (Fig. 10 E), las tobas puzolánicas son más restringidas por la predominancia de tobas líticas y mayormente de composición dacítica, estas rocas más compactas y poco meteorizadas (Fig. $10 \mathrm{~F}$ ) no tiene un potencial económico importante para su explotación artesanal debido a que para su proceso es necesario mayor inversión en extracción, trituración y pulverización.

En total se levantaron un total de 26 puntos dentro del área de estudio (Fig. 2) y como se puede ver en los resultados del ensayo de FRX (Tabla 2), todas las muestras superan estos requisitos, sin embargo, se ha visto conveniente realizar todos los ensayos solamente en 6 muestras debido a su ubicación estratégica que cubren el área del depósito. La elección de estas muestras se realiza debido a que la mayoría de las muestras (ver Tabla 1) posee una regularidad en cuantos a sus componentes químicos obtenidos del análisis de FRX que permiten tener una idea general de las características del yacimiento al momento de su evaluación.

Estas muestras son BL-A5, BL-A8, BL-A11, BL-A14, BLA16, BL-A19.

\begin{tabular}{lcc}
\multicolumn{2}{c}{ Tabla 1. Coordenadas de los puntos estudiados } \\
\cline { 2 - 3 } Código & \multicolumn{2}{c}{ Coordenadas } \\
\cline { 2 - 3 } BL-A5 & 646612 & 9557105 \\
BL-A8 & 646961 & 9557400 \\
BL-A11 & 646451 & 9558450 \\
BL-A14 & 646044 & 9557798 \\
BL-A16 & 646296 & 9557384 \\
BL-A19 & 646871 & 9557861 \\
\hline
\end{tabular}

\subsection{Fluorescencia de rayos $x(F R X)$ y Difracción de rayos $X$ (DRX)}

Se analizaron las muestras con el fin de valorar si cumplen los requisitos de la norma ASTM C618 para la determinación de puzolanas naturales, en la cual indica que la suma de porcentajes de dióxido de sílice, óxido de aluminio y óxido de hierro debe ser mayor o igual al 70\%. En la Tabla 2 se puede evidenciar que todas las muestras tienen un porcentaje superior al $66 \%$ de $\mathrm{SiO} 2$, un porcentaje superior al $15 \%$ de $\mathrm{Al} 2 \mathrm{O} 3$ y con valores mayores al 1,9\% de $\mathrm{Fe} 2 \mathrm{O} 3$, sumados estos valores superan el $70 \%$ exigido por la norma, por lo que cumplen la condición de puzolana naturales.
Tabla 2. FRX de muestras tomadas en las cuestas norte y sur SUPERFICIE DE CUESTA NORTE

\begin{tabular}{|c|c|c|c|c|c|c|c|}
\hline Muestra & $\mathrm{SiO} 2$ & $\begin{array}{c}\mathrm{Al} 2 \mathrm{O} \\
3 \\
\end{array}$ & $\mathrm{~K} 2 \mathrm{O}$ & $\mathrm{aOO}$ & $\mathrm{CiO} 2$ & $\mathrm{MnO}$ & $\begin{array}{c}\mathrm{Fe} 2 \mathrm{O} \\
3 \\
\end{array}$ \\
\hline 3L-A4 & 3.00 & 17.70 & 4.530 & 0.286 & 0.201 & 0.050 & 1.930 \\
\hline BL-A5 & 6.60 & 16.30 & 3.400 & 0.439 & 0.176 & 0.052 & 2.370 \\
\hline BL-A6 & .70 & 17.20 & 4.080 & 2 & 0.166 & 0.046 & 2.430 \\
\hline BL-A7 & 8.30 & 17.00 & 1.410 & 0.072 & 0.166 & 0.064 & 3.440 \\
\hline BL-A8 & 70.50 & 17.40 & 1.650 & 0.134 & 0.199 & 0.069 & 3.650 \\
\hline BL-A9 & 76.20 & 15.70 & 3.250 & 1.750 & 0.240 & 0.070 & 2.280 \\
\hline BL-A11 & 75.20 & 18.10 & 2.830 & 0.150 & 0.194 & 0.0796 & 2.870 \\
\hline BL-A13 & 66.60 & 22.60 & 3.570 & $\begin{array}{c}0.092 \\
7\end{array}$ & 0.148 & 0.0502 & 2.140 \\
\hline BL-A14 & 69.60 & 23.50 & 1.980 & 0.075 & 0.173 & 0.0529 & 2.810 \\
\hline BL-A16 & 72.20 & 23.50 & 1.540 & 0.104 & 0.146 & 0.0458 & 2.110 \\
\hline BL-A17 & 73.30 & 17.60 & 4.940 & & 0.172 & 58 & 2.790 \\
\hline BL-A18 & 67.3 & 25 & 3.17 & $\begin{array}{c}0.074 \\
3\end{array}$ & 0.177 & 0.0506 & 2.26 \\
\hline BL-A19 & 66.5 & 27.1 & 2.82 & 0.15 & 0.176 & 0.0523 & 2.59 \\
\hline & .46 & 19.90 & 3.01 & .28 & 0.18 & 0.06 & 2.59 \\
\hline \multicolumn{8}{|c|}{ SUPERFICIE DE CUESTA SUR } \\
\hline Muestra & $\mathrm{SiO} 2$ & $\begin{array}{c}\mathrm{Al} 2 \mathrm{O} \\
3 \\
\end{array}$ & $\mathrm{~K} 2 \mathrm{O}$ & $\mathrm{CaO}$ & $\mathrm{TiO} 2$ & $\mathrm{MnO}$ & $\mathrm{Fe} 2 \mathrm{O} 3$ \\
\hline & & 20.30 & & & 0.272 & & 1.310 \\
\hline SP-B3 & 62.40 & 22.80 & 0.541 & 2.510 & 0.785 & 0.225 & 5.380 \\
\hline SP-B4 & 61.30 & 24.90 & 0.348 & 0.215 & 0.707 & 0.078 & 4.690 \\
\hline SP-B5 & 62.9 & 22.5 & 1.76 & 0.449 & 0.651 & 0.0727 & 3.930 \\
\hline SP-B6 & 72.1 & 15.6 & 4.74 & $\begin{array}{c}0.090 \\
2 \\
\end{array}$ & 0.636 & 0.16 & 4.92 \\
\hline Promedio & 61.12 & 20.95 & 1.62 & 1.30 & 0.69 & 0.18 & 5.89 \\
\hline
\end{tabular}

Las Figuras 5A y 5B muestran el contenido de óxidos de sílice, aluminio y hierro, donde se puede evidenciar que los valores de óxido de silicio son más altos en la cuesta norte en un $10 \%$, mientras que los valores del óxido de aluminio y hierro son ligeramente superiores en un 1 a $3 \%$ respectivamente. 


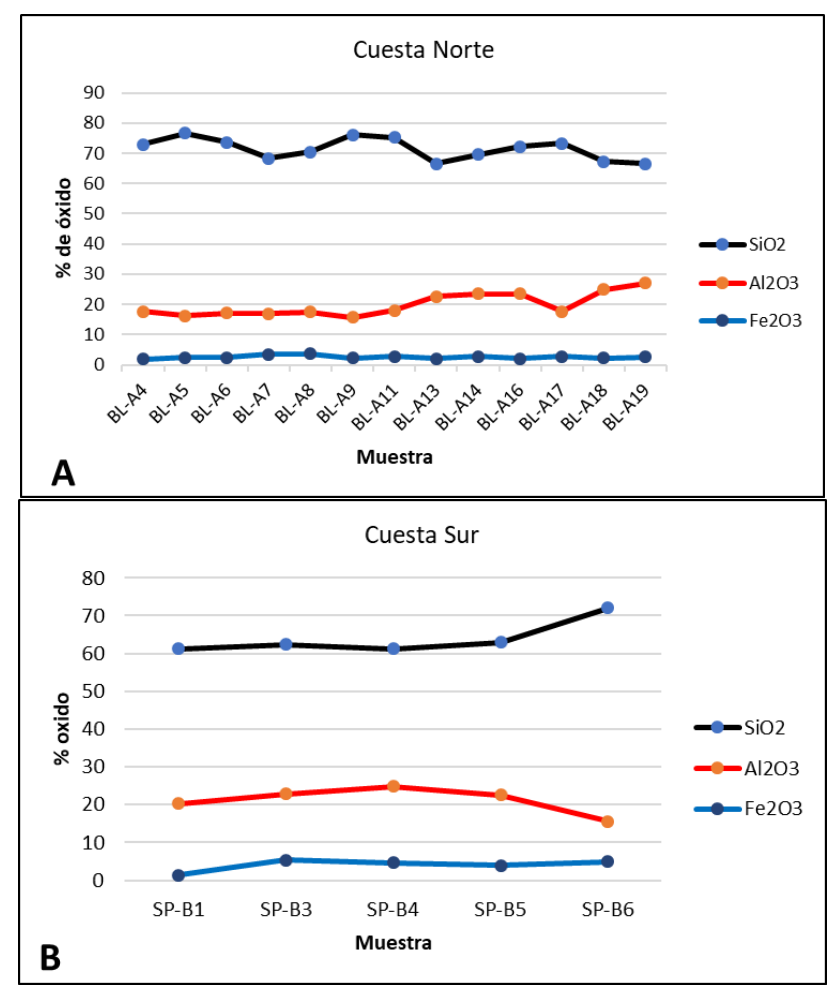

Figura 5. Relación de óxidos de sílice, aluminio y hierro, (A) cuesta norte el porcentaje de sílice es mayor que en la cuesta sur (B)

Si comparamos con las puzolanas estudiadas por el Instituto Nacional de Investigación Geológico Minero Metalúrgico (Casto, 2017) en las zonas de Panzaleo y Jachaguangu ubicadas en el cantón Pujilí de la provincia de Cotopaxi, la puzolana de Panzaleo tiene un contenido del $84.1 \%$ y la de Jachaguangu del $84.9 \%$ con el promedio de las puzolanas de Barrial Blanco en la cuesta norte que es de 93,9\%, mientras que en la cuesta sur en Sacapianga es de $85,2 \%$, demuestran que la puzolana natural del sur del Ecuador también es apta para su utilización en la producción de hormigones.

El análisis de DRX muestra que existe minerales de zeolita con porcentajes inferiores al $7 \%$ e importantes cantidades de caolinita de hasta el $33 \%$, este silicato de aluminio hidratado, de color blanco puede tener colores rojizos debido a las impurezas, el caolín le da una coloración blanquecina a todo el sector.
Tabla 3. DRX de muestras tomadas en las cuestas norte

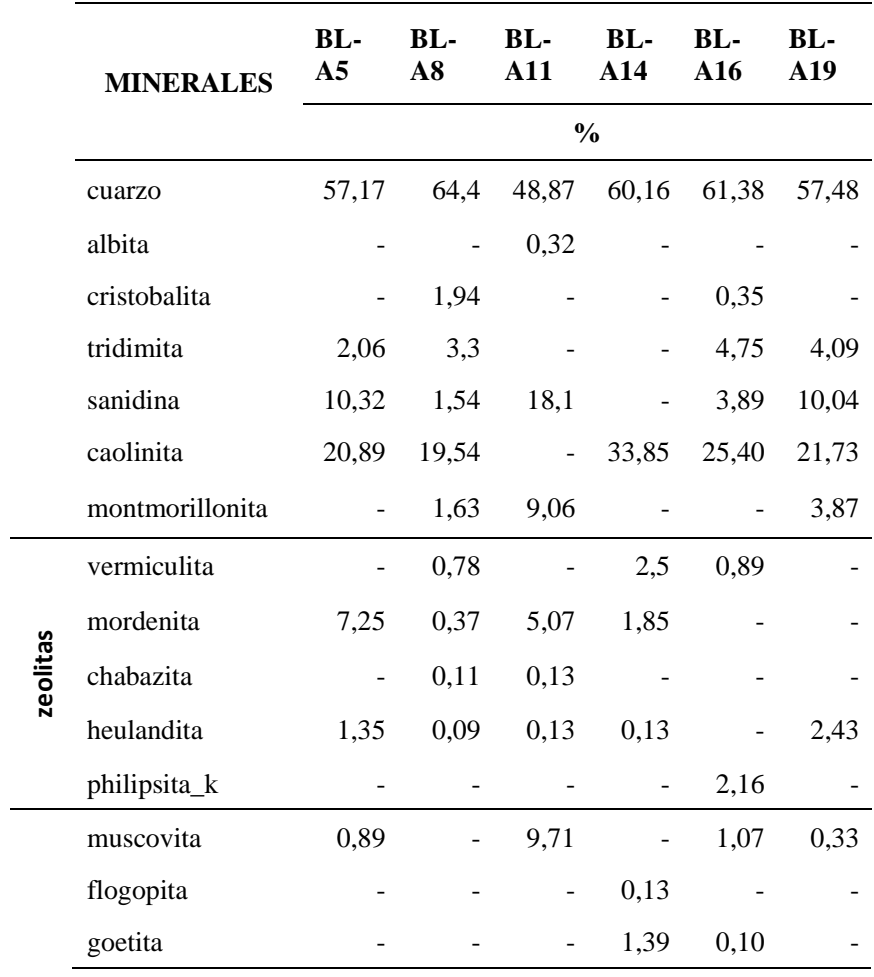

El caolín calcinado es un material cementante suplementario, dado que es un aluminosilicato activado térmicamente que a una cierta temperatura se produce una transformación de su estructura cristalina, en consecuencia, este material adquiere características similares al de la puzolana natural, las que pueden ser aprovechadas por las industrias cementeras. El cuarzo muestra porcentajes superiores al $49 \%$, aunque también contiene variedades polimorfas como la cristobalita y tridimita (Fig. 6).

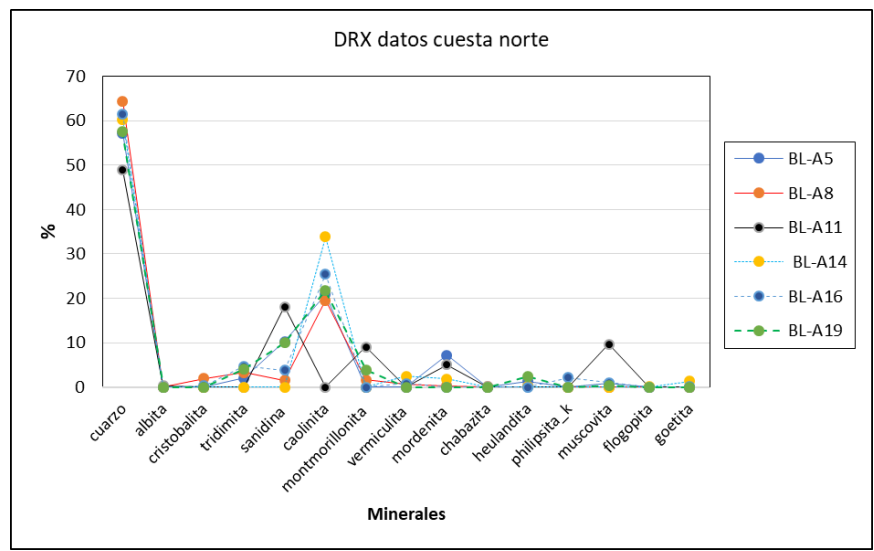

Figura 6. La presencia de cuarzo generalmente es mayor al 50\% que evidencian un ambiente volcánico ácido en la zona

Estos porcentajes están ligados con la composición riolítica por su contenido rico en sílice y feldespato alcalino (sanidina) y con cantidades menores de plagioclasa y muscovita (ver fig. 6). Las tobas riolíticas de color blanco estratificadas, en algunos casos presentan procesos de alteración que dan lugar a la formación de caolín (Fig 10 B y C), estas rocas de la Formación Loma Blanca están asignadas a un arco volcánico continental del Eoceno-Oligoceno. (Hungerbühler, 2002) 


\subsection{Pérdida por ignición}

Aplicando las especificaciones descritas en la norma ASTM C114 - 04 las muestras no superan el $10 \%$ de perdida por ignición.

Tabla 4. Resultados de pérdida por ignición

\begin{tabular}{|c|c|c|c|c|c|c|}
\hline Código & $\begin{array}{l}\text { W. } \\
\text { Crisol } \\
\text { Vacío } \\
\text { (gr) }\end{array}$ & $\begin{array}{l}\text { W. } \\
\text { Muestra } \\
\text { (gr) }\end{array}$ & $\begin{array}{l}\text { W } \\
\text { Crisol + } \\
\text { Muestra } \\
(\mathrm{gr})\end{array}$ & $\begin{array}{l}\text { W. Crisol } \\
+ \text { Muestra } \\
\text { Calcinada } \\
\text { (gr) }\end{array}$ & $\begin{array}{l}\text { W. } \\
\text { Muestra } \\
\text { Calcinada } \\
\text { (gr) }\end{array}$ & $\begin{array}{l}\text { Pérdida } \\
\text { por } \\
\text { ignición } \\
(\%)\end{array}$ \\
\hline BL-A5 & 25,47 & 1,43 & 26,90 & 26,80 & 0,10 & 6,99 \\
\hline BL-A8 & 25,69 & 1,61 & 27,30 & 27,22 & 0,08 & 4,97 \\
\hline $\begin{array}{l}\text { BL- } \\
\text { A11 }\end{array}$ & 14,11 & 1,38 & 15,49 & 15,42 & 0,07 & 5,07 \\
\hline $\begin{array}{l}\text { BL- } \\
\text { A14 }\end{array}$ & 25,81 & 1,77 & 27,57 & 27,50 & 0,07 & 3,95 \\
\hline $\begin{array}{l}\text { BL- } \\
\text { A16 }\end{array}$ & 15,67 & 1,26 & 16,93 & 16,88 & 0,05 & 3,97 \\
\hline $\begin{array}{l}\text { BL- } \\
\text { A19 }\end{array}$ & 26,33 & 1,84 & 28,17 & 28,06 & 0,11 & 5,98 \\
\hline
\end{tabular}

\subsection{Peso específico}

El ensayo se lo practica de acuerdo a la norma ASTM C 18817 , y se hicieron para las 6 muestras, los análisis realizados indican un promedio total de $2,496 \mathrm{gr} / \mathrm{cm}^{3}$ para las rocas tobáceas.

Tabla 5. Resultados de peso específico

\begin{tabular}{|c|c|c|c|c|c|c|c|}
\hline \multirow[b]{2}{*}{$\begin{array}{l}\text { Códig } \\
\text { o }\end{array}$} & \multirow[b]{2}{*}{$\begin{array}{l}\mathrm{N}^{\circ} \\
\text { Ens } \\
\text { ayo }\end{array}$} & \multicolumn{4}{|c|}{ Parámetro } & \multicolumn{2}{|c|}{ Peso específico } \\
\hline & & $\mathrm{P} 1$ & $\mathrm{P} 2$ & P3 & $\mathrm{P} 4$ & $\begin{array}{l}\mathrm{Pe} \\
\mathrm{gr} / \mathrm{cm} 3\end{array}$ & $\begin{array}{l}\text { Prome } \\
\text { dio } \\
\mathrm{gr} / \mathrm{cm} \\
3\end{array}$ \\
\hline \multirow{3}{*}{$\begin{array}{l}\text { BL- } \\
\text { A5 }\end{array}$} & 1 & 8,74 & 9,62 & 13,69 & 14,21 & 2,44 & \multirow{3}{*}{2,39} \\
\hline & 2 & 9,25 & 10,45 & 15,76 & 16,45 & 2,35 & \\
\hline & 3 & 9,27 & 10,08 & 14,52 & 14,99 & 2,38 & \\
\hline \multirow{3}{*}{$\begin{array}{l}\text { BL- } \\
\text { A8 }\end{array}$} & 1 & 9,25 & 10,88 & 15,77 & 16,73 & 2,43 & \multirow{3}{*}{2,43} \\
\hline & 2 & 8,70 & 9,71 & 13,76 & 14,34 & 2,35 & \\
\hline & 3 & 9,26 & 10,62 & 14,50 & 15,32 & 2,52 & \\
\hline \multirow{3}{*}{$\begin{array}{l}\text { BL- } \\
\text { A11 }\end{array}$} & 1 & 9,26 & 10,47 & 14,53 & 15,23 & 2,37 & \multirow{3}{*}{2,43} \\
\hline & 2 & 8,72 & 9,91 & 13,74 & 14,44 & 2,43 & \\
\hline & 3 & 8,70 & 10,12 & 13,79 & 14,64 & 2,49 & \\
\hline \multirow{3}{*}{$\begin{array}{l}\text { BL- } \\
\text { A14 }\end{array}$} & 1 & 9,24 & 11,40 & 15,81 & 17,17 & 2,70 & \multirow{3}{*}{2,61} \\
\hline & 2 & 9,26 & 10,63 & 14,50 & 15,32 & 2,49 & \\
\hline & 3 & 8,70 & 10,07 & 13,75 & 14,60 & 2,63 & \\
\hline \multirow{3}{*}{$\begin{array}{l}\text { BL- } \\
\text { A16 }\end{array}$} & 1 & 9,26 & 10,53 & 14,55 & 15,28 & 2,35 & \multirow{3}{*}{2,57} \\
\hline & 2 & 8,73 & 10,09 & 13,70 & 14,57 & 2,78 & \\
\hline & 3 & 925 & 10,92 & 15,79 & 16,81 & 2,57 & \\
\hline \multirow{3}{*}{$\begin{array}{l}\text { BL- } \\
\text { A19 }\end{array}$} & 1 & 8,73 & 9,98 & 13,70 & 14,47 & 2,60 & \multirow{3}{*}{2,55} \\
\hline & 2 & 8,70 & 10,11 & 13,75 & 14,61 & 2,56 & \\
\hline & 3 & 8,73 & 10,36 & 13,70 & 14,67 & 2,47 & \\
\hline \multicolumn{7}{|c|}{ Promedio total } & $\begin{array}{l}2.496 \\
\mathrm{gr} / \mathrm{cm} \\
3\end{array}$ \\
\hline
\end{tabular}

\section{4. Índice de actividad puzolánica}

La Tabla 6 y Figura 7 muestra los resultados de este análisis, lo cual evidencia que casi todas las muestras cumplen esta condición con excepción de la muestra BL-A8 y BL-A11 que está ligeramente por debajo del valor establecido (<75\%).

Tabla 6. Resultados del índice de actividad puzolánica

\begin{tabular}{|c|c|c|c|c|c|c|}
\hline & \multirow{2}{*}{ Nro/Código } & \multicolumn{3}{|c|}{$\begin{array}{l}\text { Resistencia a los } 7 \text { dias } \\
(\mathrm{MPa})\end{array}$} & \multirow{2}{*}{$\begin{array}{c}\text { Resistenc } \\
\text { ia } \\
\text { Promedio } \\
\text { (Mpa) }\end{array}$} & \multirow{2}{*}{$\begin{array}{l}\text { Índice de } \\
\text { Puzolanid } \\
\text { ad (\%) }\end{array}$} \\
\hline & & $\begin{array}{c}\text { Morter } \\
\text { o \#1 }\end{array}$ & $\begin{array}{c}\text { Morter } \\
\text { o\#2 }\end{array}$ & $\begin{array}{c}\text { Morter } \\
\text { o\#3 }\end{array}$ & & \\
\hline 1. & $\begin{array}{l}\text { Mortero de } \\
\text { Control }\end{array}$ & 13,89 & 13,52 & 13,44 & 13,62 & \\
\hline 2. & BL-A5 & 12,67 & 11,39 & 7,98 & 10,68 & 78,42 \\
\hline 3. & BL-A8 & 9,92 & 10,47 & 8,78 & 9,72 & 71,40 \\
\hline 4. & BL-A11 & 10,14 & 8,97 & 11,22 & 10,11 & 74,22 \\
\hline 5. & BL-A14 & 11,41 & 13,56 & 12,21 & 12,39 & 91,01 \\
\hline 6. & BL-A16 & 12,72 & 13,17 & 12,08 & 12,66 & 92,96 \\
\hline 7. & BL-A19 & 12,69 & 12,17 & 14,14 & 13,00 & 95,49 \\
\hline
\end{tabular}

\section{Resistencia a la compresión de morteros}

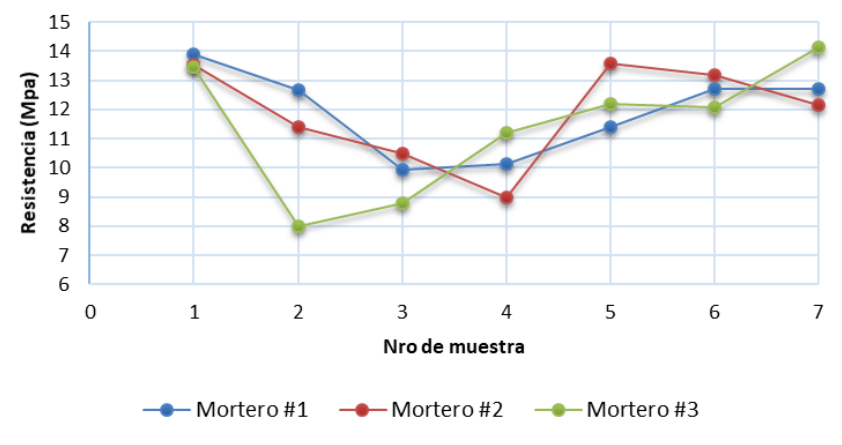

Figura 7. Resistencia a la compresión de morteros a los 7 días de curado

A pesar de que las muestras 3 y 4 de la Tabla 6 muestra resultados por debajo del $75 \%$ de puzolanidad, su resistencia a la compresión es mayor a la de un ladrillo convencional pues soportan cargas mayores a 9 Mpa (Fig 7); es decir aproximadamente $90 \mathrm{Kg} / \mathrm{cm}^{2}$.

\subsection{Geofísica para determinar la potencia del recurso}

Una vez conocido el contexto geológico en superficie, es necesario tener una idea de la potencia en profundidad del recurso puzolánico. Para ello se realizó dos líneas de tomografía ubicadas estratégicamente de forma perpendicular al buzamiento de las capas geológicas; con dirección preferencial suroeste - noreste (ver fig. 2). En los dos perfiles de geofísica se pudo identificar la variación de resistividad que delimita de forma clara las litologías presentes, así la arenisca presenta una resistividad eléctrica de 100 a $6.4 \times 10^{8} \Omega \mathrm{m}$, conglomerados con valores de 20 a 110 $\Omega \mathrm{m}$ y las tobas puzolánicas con rango de $2 \times 10^{3}$ a $10^{5} \Omega \mathrm{m}$. Al existir gran variabilidad de resistividades (Fig. 8), es notorio la potencia de la capa de puzolanas, correspondiente a un promedio entre 15 y 20 metros, sin embargo, existen zonas 
donde esta potencia asciende hasta los 60 metros como lo que se evidencia en la tomografía del perfil 1 en la zona naranja (Fig. 8), debido a ello en los perfiles realizados donde no hay datos de potencia se toma como valor promedio una potencia de $40 \mathrm{~m}$.

Los perfiles geofísicos realizados en este estudio fue únicamente para deducir el espesor de la toba, permite además ver claramente la presencia de varios cuerpos de roca saturada con agua (resistividad $<5 \Omega \mathrm{m}$ ) de gran tamaño, considerando que el ensayo fue realizado en época de lluvia, se deduce por lo tanto que los conglomerados y areniscas tienen esta capacidad de almacenar agua que podría ser aprovechado en épocas de verano por los pobladores del valle.

\subsection{Cálculo del recurso}

Los cálculos de volumen del yacimiento son a partir de la metodología previamente descrita, usando las fórmulas (1,2 y 3) del cálculo de reservas.
La Tabla 7 muestra los volúmenes obtenidos de las diferentes secciones realizadas

Tabla 7. Cálculo de volúmenes por método de perfiles geológicos

\begin{tabular}{cccc}
\hline PERFIL & $\begin{array}{c}\text { AREA DE } \\
\text { SECCION } \\
(\mathrm{m} 2)\end{array}$ & $\begin{array}{c}\text { DISTANCIA } \\
\text { ENTRE PERFIL } \\
(\mathrm{m})\end{array}$ & $\begin{array}{c}\text { VOLUMEN } \\
(\mathrm{m} 3)\end{array}$ \\
\hline A-B & 35783 & 400 & 22515400 \\
B-C & 76794 & 400 & 32331200 \\
C-D & 84862 & 400 & 37714600 \\
D-E & 103711 & 400 & 26427000 \\
\hline Zona limite & 84973 & 188 & 7987462 \\
1 & & 188 & 2496350 \\
Zona limite & 49927 & & \\
2 & & &
\end{tabular}

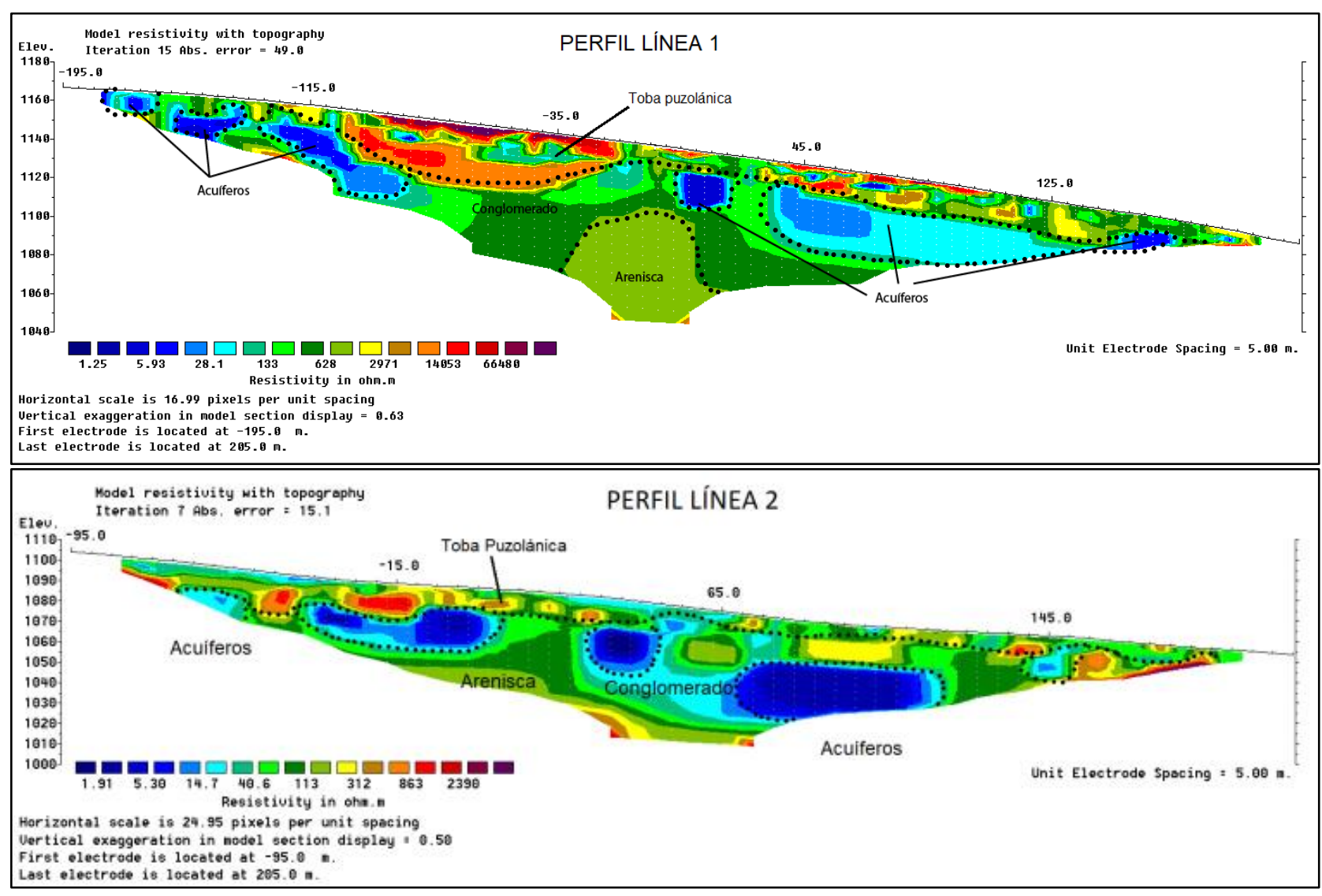

Figura 8. Perfil geofísico línea 1 y línea 2 realizado en la cuesta norte, nótese que las tobas se ajustan al paleo-relieve de la zona, las resistividades más bajas indican la presencia de acuíferos 

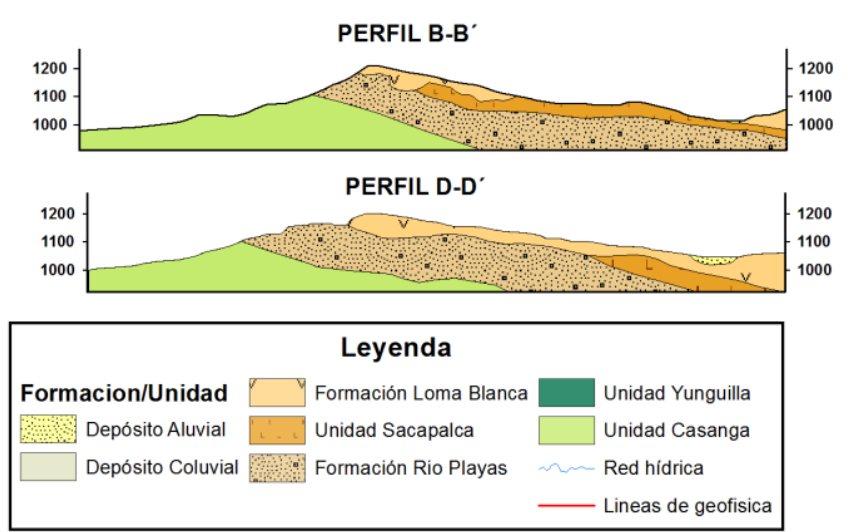

Figura 9. Perfiles geológicos B y D dispuestos en la cuesta norte como parte del cálculo de recursos

El Volumen total es de $129472012 \mathrm{~m}^{3}$, el tonelaje total tomando en cuenta el peso específico de la roca de $2,5 \mathrm{t} / \mathrm{m} 3$ es de 323680030 t.

Con todos estos resultados podemos decir que el yacimiento de puzolana se mantiene dentro de los parámetros establecidos por el índice JORC (1999) para ser un recurso mineral indicado que
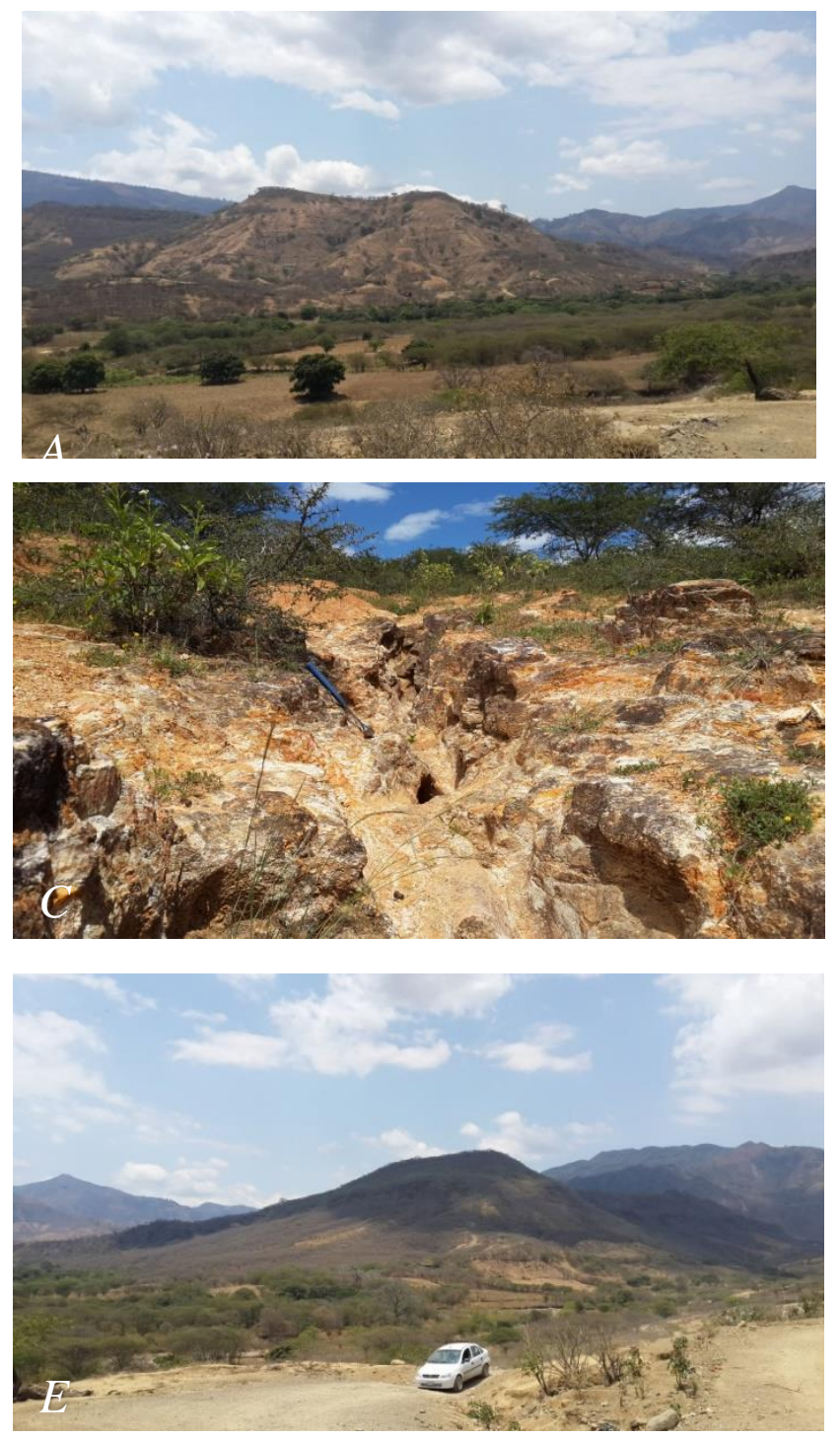

se ha estimado con un nivel razonable de confianza el tonelaje, densidad, forma, características físicas, ley y contenido mineral basado en información sobre exploración, muestreo y pruebas reunidas mediante técnicas apropiadas en afloramientos y geofísica. Las ubicaciones están demasiado espaciadas o su espaciamiento es inapropiado para confirmar la continuidad geológica y/o de ley, pero está espaciada con suficiente cercanía para que se pueda suponer continuidad. Por ende, con un estudio más minucioso y perforaciones podría subir de categoría.

\subsection{Coeficiente de destape}

Para el cálculo del volumen del material estéril se realiza el mismo método que para calcular el área de la capa puzolánica, obteniendo un valor de 1773248 metros cuadrados multiplicados por 0,3 metros de profundidad del suelo, quedando 531974,4 m3 de capa estéril.

Por lo tanto, el coeficiente de destape es de 0,00109 m3/Ton, con este valor se pretende demostrar que el recurso puzolánico es muy eficiente para su extracción por su coeficiente de destape menor al $1 \%$, indicando que los costos de destape a su vez también serán mínimos.
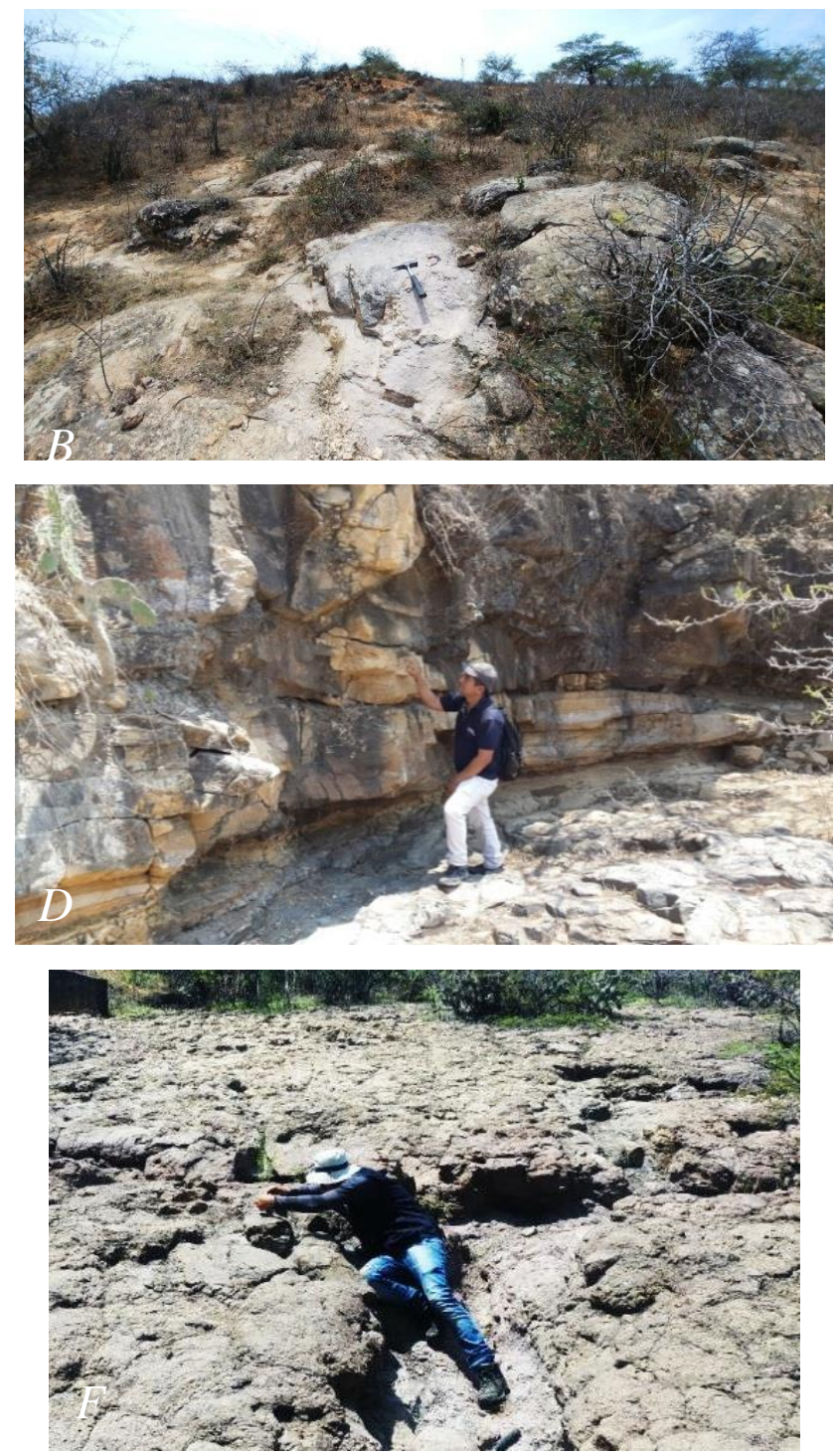

Figura 10. Mosaico de afloramientos: A. Frente de Cuesta norte, B, C. afloramientos de tobas de cristales meteorizadas blanquecinas y amarillas, D. Contacto entre Tobas de cristales y tobas líticas en la base. E. Frente de Cuesta Sur, F. Afloramiento de tobas líticas en Sacapianga 


\section{CONCLUSIONES}

Se identificó tres tipos de tobas presentes dentro del área de estudio, las primeras descritas como tobas de cristales con características puzolánicas ubicadas en la parte oeste cerca de Barrial Blanco, las segundas identificadas como tobas de cristales silicificadas ubicadas en contacto fallado con las tobas antes descritas y las terceras como tobas líticas localizadas en la zona este cerca de Sacapianga.

Todas las muestras analizadas con FRX cumplen la norma ASTM C 618 "Standard Specification for Coal Fly Ash and Raw or Calciner Natural Pozzolan For Use in Concrete", en donde la suma total de la composición química del material entre la cantidad de sílice, aluminosilicatos y óxidos de hierro son mayores al $70 \%$. Comparadas con puzolanas del norte del país como las de Panzaleo y Jachaguangu ubicadas en el cantón Pujilí de la provincia de Cotopaxi, demuestran que la puzolana natural del sur del Ecuador también es apta para su utilización en la construcción de viviendas de interés social.

Los resultados muestran que todas las muestras no superan el $10 \%$ de perdida por ignición. Y el peso específico en promedio es $2.496 \mathrm{gr} / \mathrm{cm} 3$.

De acuerdo con los parámetros de la norma ASTM C 618 únicamente cumplen actividad puzolánica las tobas de cristales de la cuesta norte perteneciente a Barrial Blanco con valores de 71 a $95 \%$ de índice de puzolanidad, de las cuales los resultados de DRX determinaron cristales de cuarzo, tridimita, sanidina, caolinita, muscovita, montmorillonita, vermiculita, albita, goetita, y del grupo de zeolitas se encuentra mordenita, chabazita, heulandita, philipsita y chabazita, además de gran cantidad de vidrio volcánico. Debido a la alta meteorización del lugar, los feldespatos están siendo alterados en caolinita. Estos resultados indican que las rocas son de composición riolítica por su contenido rico en sílice y feldespato alcalino (sanidina) en concordancia con INIGEMM mencionado en la carta de Cariamanga.

No resultó factible el cálculo y evaluación de la capa de puzolana en la cuesta sur en Sacapianga debido a que posee una exuberante vegetación con respecto a la cuesta norte.

Los resultados de la tomografía de resistividad eléctrica confirmaron una profundidad promedio de la capa puzolánica de entre 15 y 40 metros donde es visible algunos cuerpos acuíferos contenidos en conglomerados debajo de las tobas. Dichos acuíferos constituyen zonas que podrían aportar agua en época de verano si se explotan adecuadamente.

El volumen y tonelaje de la puzolana en la cuesta de Barrial blanco es de 323680030 toneladas. El yacimiento de puzolana se mantiene como un recurso mineral indicado dentro de los parámetros de categorización JORC, (1999) estimado con un nivel razonable de confianza el tonelaje, densidad, forma, características físicas, ley y contenido mineral, basado en información sobre exploración, muestreo y pruebas reunidas mediante técnicas apropiadas en afloramientos y geofísica.
Finalmente la puzolana de Barrial Blanco por su estado de meteorización dominante y su escaso recubrimiento estéril no requiere de costos elevados de inversión para su extracción y proceso de trituración y molienda, no obstante existen lugares donde habría que utilizar máquinas para excavar y obtenerla, sin embargo comparando con la explotación de canteras y procesos de producción para la obtención de cemento, los costos son más bajos, y se podría fomentar la creación de nuevas plazas de trabajo en la explotación de puzolanas para la elaboración de baldosas y bloques como material para la industria de la construcción de viviendas de bajo coste, necesarias en el sur del Ecuador.

\section{AGRADECIMIENTO}

Los autores agradecen la ayuda brindada a los docentes del laboratorio mineralogía, geofísica Ing. Yan Jumbo, resistencia de materiales, mecánica de suelos Mgtr. Berenice Zúñiga e Ing. Diego Mata del Departamento de Geología y Minas e Ingeniería Civil de la UTPL por las facilidades prestadas para la ejecución de la presente investigación.

\section{REFERENCIAS}

ASTM. (2003). C184-02 "Standar Test Method For Finess Of Hydraulic Cement By The 150-Micrometer (No.100) And 75-Micrometer (No.200) Sieves (Aashto T128)".

ASTM. (2002). C184-94 "Standard Test Method for Fineness of Hydraulic Cement by the $150-\mu \mathrm{m}$ (No. 100) and

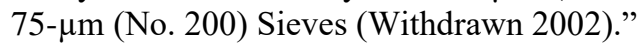

ASTM. (2003). C114-04 "Standard Test Methods for Chemical Analysis of Hydraulic Cement."

ASTM. (2003). C311-02 "Standard Test Methods for Sampling and Testing Fly Ash or Natural Pozzolans for Use as a Mineral Admixture in Portland-Cement Concrete."

ASTM. (2003). C618 "Standard Specification for Coal Fly Ash and Raw or Calcined Natural Pozzolan for Use in Concrete.

Bustillo, M., y López, C. (1997). Manual de evaluación y diseño de explotaciones mineras. Entorno Gráfico. Retrieved from https://scholar.google.es/scholar?hl=es\&as_sdt=0\%2 $\mathrm{C} 5 \& \mathrm{q}=$ lopez+jimeno+manual+de+evaluacion $+\mathrm{y}+\mathrm{ex}$ plotacion $\&$ btnG $=($ Febrero, 2018)

Campoverde, W., \& Narvaéz, L. (2017). Caracterización y Evaluación de Las Puzolanas del Cantón Gonzanáma y Paltas. Universidad Técnica Particular de Loja. Obtenido de http://dspace.utpl.edu.ec/handle/123456789/18392. (Mayo, 2018).

Castro, C. M. J., Albear, J. J. H., Alcivar, M. S. G., \& Brito, S. (2017). Impacto de la utilización de puzolanas 
naturales ecuatorianas. Revista de Investigaciones en Energía, Medio Ambiente y Tecnología: RIEMAT ISSN: $\quad 2588-0721,2(1)$ 1-5 https://doi.org/10.33936/riemat.v2i1.931

Egüez A. y Poma O. (2001). La Cuenca Alamor-Lancones en el contexto geodinámico de los Andes de Huancabamba, SW Ecuador. Cuartas Jornadas en Ciencias de la Tierra, Memorias, Escuela Politécnica Nacional. pp 19-22.

GAD Paltas. (2015). Matriz de plan de desarrollo y ordenamiento territorial. Retrieved from http://app.sni.gob.ec/snilink/sni/PORTAL_SNI/data_sigad_plus/sigadplusdia gnostico/1160027520001_DIAGNÓSTICO ULTIMO YAMANA_05-10-2015_08-52-44.pdf

Hungerbühler, D., Steinmann, M., Winkler, W., Seward, D., Egüez, A., Peterson, D. E., Hammer, C. (2002). Neogene stratigraphy and Andean geodynamics of southern Ecuador. Earth-Science Reviews, 57(1-2), 75-124. https://doi.org/10.1016/S00128252(01)00071-X

INIGEMM. (2017). Hoja geológica Cariamanga, Escala $1: 100000$.

Jaillard, E., Laubacher, G., Bengtson, P., Dhondt, A. V., \& Bulot, L. G. (1999). Stratigraphy and evolution of the Cretaceous forearc Celica-Lancones basin of southwestern Ecuador. Journal of South American Earth Sciences, 12(1), 51-68. https://doi.org/10.1016/S0895-9811(99)00006-1.

JORC, (1999), Australasian code for reporting of mineral resources and ore reserves (the JORC code), Joint Ore Reserve Committee of the Australasian Institute of Mining and Metallurgy, Australian Institute of Geoscientists and Minerals Council of Australia, 16 p.

Kennerley, J. B. (1973). Geology of the Loja Province, Southern Ecuador. Institute of Geological Sciences, Report, 23, 1-34.

Malla, K. (2017). Caracterización y evaluación de puzolanas en el cantón Saraguro. Universidad Tecnica Particular de Loja. Obtenido de: http://dspace.utpl.edu.ec/handle/123456789/17544. (Mayo 2018).

Paladines, A, Soto, J. (2010). Geología y yacimientos minerales del Ecuador Agustín Paladines - Loja, Ecuador : UTPL, 311 p.

Stephenson, P, R. (2001) The JORC code, Applied Earth Science, $\quad 110: 3, \quad 121-125$, DOI:10.1179/aes.2001.110.3.121

Steinmann, M., Hungerbühler, D., Seward, D., \& Winkler, W. (1999). Neogene tectonic evolution and exhumation of the southern Ecuadorian Andes: A combined stratigraphy and fission-track approach. Tectonophysics, 307(3-4), 255-276. https://doi.org/10.1016/S0040-1951(99)00100-6.

Telford, W. M., Geldart, L. P., \& Sheriff, R. E. (1990). Applied Geophysics. Book. https://doi.org/10.1180/minmag.1982.046.341.32

Valarezo Cuenca, M. E. (2017). Una sub-cuenca de antearco pre-acrecionaria del cretácico tardío: sub-cuenca río playas, sur del Ecuador. Tesis ingeniería. Escuela Politécnica Nacional, Quito, Ecuador.

\section{BIOGRAFÍAS}

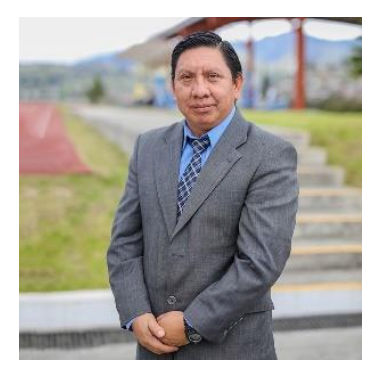

Galo Alexander Guamán Jaramillo, Ingeniero en Geología y Minas por la Universidad Técnica Particular de Loja en 2002, con Diplomado y Maestría en Sistemas de Información Geográfica en 2010 por la Universidad San Francisco de Quito. Experiencia laboral como geólogo en la empresa de vialidad del Sur Loja (VIALSUREP), técnico de geomorfología en el Instituto de Investigaciones Espaciales IEE (exCLIRSEN), técnico de catastro y analista minero en la Agencia de Regulación y Control Minero (ARCOM), consultor privado en geología, geotecnia y cartografía en la empresa GCA Consultores, técnico geomorfólogo del Herbario Loja y Programa Podocarpus en proyectos de zonificación ecológica. Actualmente docente en la UTPL en la carrera de ingeniería en geología y candidato a doctor en Ciencias de la Tierra en la Universidad de Granada-España.

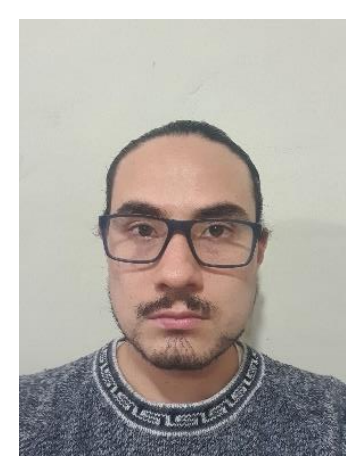

Carlos Fernando Ubidia Terán, graduado como Ingeniero en Geología y Minas en la Universidad Técnica Particular de Loja y egresado de la maestría de Planificación y Diseño de Minas de la Cámara Minera del Perú. Nacido en la ciudad de Cotacachi Imbabura el 10 de Julio de 1995. Experiencia profesional como Técnico de Planificación y Ordenamiento Territorial en el GADM Zaruma, actualmente ejerce como consultor independiente de fotogrametría, topografía y geología. 


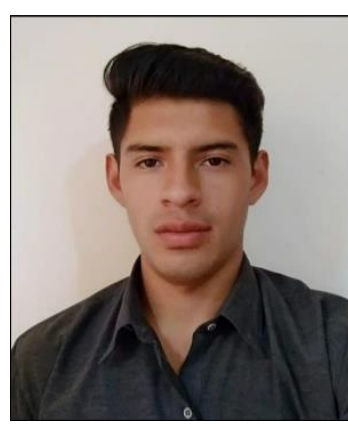

Wilman Fernando Gualpa

Guaycha, Ingeniero en Geología y

Minas (2018). Graduado en la

Universidad Técnica Particular de

Loja. Nació en la ciudad de Loja,

Ecuador en 1996. Se desempeñó

como Técnico en el Departamento

Geológico Minero en la compañía

AGRIMROC S.A. Actualmente

forma parte de la unidad cartográfica del Instituto Nacional

de Estadísticas y Censos (INEC). 